\section{US drug companies push for changes in recombinant DNA guidelines}

\section{David Dickson reports that fears of industrial espionage are making drug companies reluctant to comply with rules covering genetic engineering research}

US pharmaceutical manufacturers are challenging a key section of the National Institutes of Health's guidelines covering recombinant DNA research, claiming that compliance under present procedures could lead to the disclosure of proprietary information to potential competitors.

The section in question is that which specifies the conditions under which certain experiments can be exempted from a prohibition on research involving more than 10 litres of culture-a situation which many companies are rapidly approaching as recombinant DNA technology moves from the research to the production stage.

Under an interim procedure agreed by the NIH's Recombinant DNA Advisory Committee (RAC) last month, applications for such exemptions have to be circulated to all members of the committee, and approved by a threeperson subcommittee, before they can be granted by the director of NIH, Dr Donald Fredrickson.

Although legal provisions exist covering what may or may not be divulged by RAC members as "special government employees", Dr Fredrickson has said that he cannot guarantee the complete confidentiality of information submitted to the RAC as part of this approval procedure.

On the other hand, regulations covering the use of recombinant DNA techniques in private industry which are currently being drawn up by the Food and Drug Administration-and which will provide statutory protection for proprietary information-are not at present scheduled to be on the statute book before February 1980.

In the interim, unless an alternative way is found of protecting such information, pharmacuetical companies and other groups pursuing recombinant DNA research who need to go beyond the 10-litre limit as a step towards fullscale production, but do not want to divulge too much information to a potential competitor, have been faced with some hard choices.

Some, such as the Berkeley-based Cetus Corporation which is required by local laws to observe the NIH guidelines, plan to hold back on any experiments for which providing full details to the NIH would, they feel, prejudice their proprietary rights.
In contrast, the San Francisco firm Genentech is planning to take what one pharmaceutical industry official calls a "calculated risk" in conducting scaled up experiments according to the technical criteria that have been laid down by NIH, but without seeking the NIH's formal approval (although NIH will be informed when such experiments take place).

"To get the full benefits of this techto volumes greater than 10 litres", $\mathrm{Mr}$ Robert A. Swanson, president of Genentech, told Nature last week. He added, however, that there was no mechanism for doing this through NIH at present "that would take into account the necessity to protect proprietary information".

(Eli Lilley, the pharmaceutical company which has entered an agreement with Genentech to develop techniques for producing insulin, has suggested to the FDA that its proposed regulations -which are likely to require companies to show that a product has been developed under the NIH guidelines"should include provisions for exempting studies commenced prior to the effective date of the guidelines or regulations".)

Issues related to the confidentiality of information, although they have been heatedly debated over the past two years in Britain's Genetic Manipulation Advisory Group, have tended to remain on the sidelines within the US debate, where greater attention has been given to public concern about the potential health hazards of the research.

As the production of substances such as insulin, growth hormone and interferon using recombinant DNA techniques comes closer to reality, however, companies which have agreed to comply voluntarily with the NIH guidelines are becoming increasingly concerned about being required to divulge commercially valuable information.

"There are not many companies wanting to do so at the present time, but within the next year or two you will have a lot of companies wanting to scale-up their research. And how you deal with proprietary information in such circumstances is causing some concern", says Dr Herbert Weissbach of the Roche Institute of Molecular Biology. nology out, it is important to go rapidly

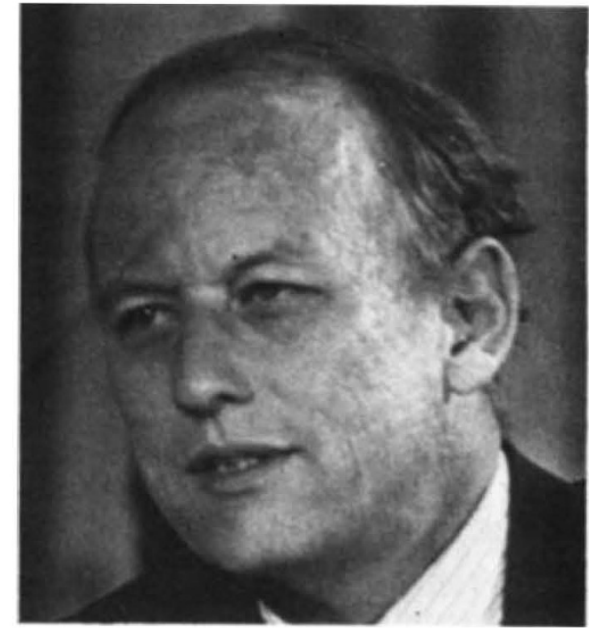

Dr Donald Fredrickson, Director of the NIH: under pressure on confidentiality

These sentiments are echoed by $\mathrm{Dr}$ John Adams, vice-president of the Pharmaceutical Manufacturers Association in Washington. "We do not feel that the NIH guidelines in their current form adequately address the problems that we have with regard to protecting the confidentiality of information. The problem is that there is nothing in the statutes of NIH that covers trade secrets."

At the same time, however, trade union and public interest groups are arguing that the more recombinant DNA techniques become part of standard production techniques, the greater the potential for serious health effects-and hence the greater the need for information about the processes involved.

Under the terms of the guidelines published by NIH last December, experiments requiring more than 10 litres of culture are prohibited unless the recombinant DNA's are rigorously characterised and "the absence of harmful sequences established". In such cases, the guidelines state that the experiments can be authorised by the director of NIH "under procedures specified by the RAC".

Exactly what these procedures should be is now under debate. At a meeting of the advisory committee held in Bethesda last month, $\mathrm{Dr}$ William Gartland, head of the NIH's Office of Recombinant DNA Activities (ORDA) suggested that as an interim procedure, applications for scaled-up experiments should be reviewed by the chairperson and two other members of the RAC.

This group, he suggested, would recommend whether the request should be approved by ORDA or whether it required review by the full committee, in which case a subcomittee of the RAC would review the application prior to it being passed to the full committee.

Various members of the committee objected to this procedure, claiming that all members of the RAC should 
receive details of all applications for scale up. "Otherwise the sub-group could theoretically be given a blank cheque to pass experiments without reference to the full committee" says committee member Dr Karim Ahmed.

After a certain amount of debate, it was agreed that until the next meeting of the advisory committee in May, any application for experiments over 10 litres would be examined by a threeperson subgroup, but would also be circulated to all members of the committee one week prior to the subgroup's meeting (so far no such application has been received by NIH).

The next RAC meeting will also consider the report of a subcommittee set up by chairperson Dr Jane Setlow on how the phrase "the absence of harmful sequences" should be interpreted. Some have argued that even an insulin producing gene might be described as potentially harmful, depending on where it was functioning; and $\mathrm{Dr}$ Setlow is keen to ensure a reasonable uniformity of interpretation between different institutional biohazard committees (IBCs), which are already required to make such judgements in certain circumstances.

The major question regarding procedure, however, is whether the pharmaceutical companies, if they are required by the FDA to comply with the NIH guidelines, are prepared to accept the proposed arrangements as adequate to protect proprietary information; and conversely whether an alternative arrangement more to their liking will be acceptable to all members -and in particular the "public interest" representatives-on the advisory committee.

Already at least one company has approached Dr Fredrickson to see if he could give his approval to certain scaled-up experiments without consulting the RAC. But Dr Fredrickson has informed them that, under his interpretation of the current guidelines. there is no way this can be done.

The pharmaceutical companies are now focusing attention on the form of regulations which the FDA is likely to bring in, following its announcement last December that it was proposing to require that any firm seeking approval of a product "requiring the use of recombinant DNA methods in its development or manufacture" demonstrate its compliance with the requirements of the NIH guidelines.

According to FDA Commissioner Dr Donald Kennedy, the agency is confident that it can find some way to protect proprictary information as it does now with other commercial products, even if this information has to be submitted to NIH for approval. But the drug companies are not so confident, and indeed are challenging whether the FDA has the right to regulate the process, in addition to the product, of research.

"It may be difficult to show that any particular research protocol involves a specific trade secret", says Dr C. W. Pettinga, executive vice president of Eli Lilley which has been saying for some time that the need to conduct experiments involving more than 10 litres of culture is imminent, and is keen to press ahead with its own insulin research. "Also it may be possible for a competitor to determine from a series of protocols the general thrust of research activity that in part or in whole might be valuable proprietary information."

In comments to the FDA which $\mathrm{Dr}$ Adams of the Pharmaceutical Manufacturer's Association says are broadly supported in the industry, Dr Pettinga warns that unless information can be submitted in confidence to the members of the RAC, there is the danger of the premature disclosure of a potentially patentable idea "which would almost certainly preclude patent protection in most foreign countries".

\section{Scale-up a local problem}

He suggests that authority to increase the 10-litre limit, in a manner consistent with appropriate containment standards, be given to local institutional biohazard committees (which would also be empowered to approve the utilisation of host-vector systems and research protocols for all except experiments requiring the highest level of containment).

In broader terms, Dr Pettinga, with the support of other members of the PMA, says that "the regulation of basic research by FDA is not desirable". And he suggests a mecanism should be developed for voluntary compliance with NIH guidelines, and that FDA should remain involved solely

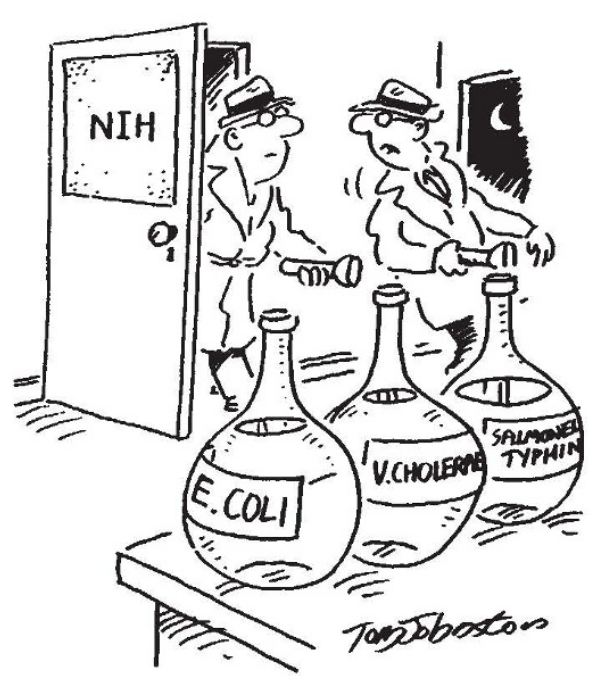

"Be careful! This place may be bugged!" with procedures regarding the safety and efficacy of drugs, and not the regulation of research.

How FDA and NIH respond to these recommendations remains to be seen. Already there are disagreements over what constitutes adequate protection of potentially valuable information. NIH, for example, has suggested that to defend proprietary rights, institutions should apply for a patent before submitting information to the RAC; the pharmaceutical companies have replied that in most cases this is unlikely to work, since a potentially patentable discovery will be based on work that requires registration and/or approval before it can be carried out.

All sides are agreed, however, that the current situation is unclear. "We are hoping that somewhere down the road the rules of the game will be clarified and that reason will prevail. At present it is total confusion as far as we are concerned", Mr Peter Farley, vice-president of Cetus, said last week.

"Within the year we will be very concerned about the precise scale-up requirements. We will then have to pick and choose on a case by case basis whether to disclose full information of our plans to the NIH; if we were doing something very clever, the details of which we did not want others to know about, then for the time being we would do nothing."

One issue to be decided is how much information would need to be divulged to the NIH before a certain experiment would be approved as safe. "The characterisation of the gene presents no problem at all, since we would want to do: this for our own safety. But describing specifically what one has done or providing the justification for going to larger volumes could involve sensitive information" says Dr Joseph Grady, of Upjohn Co.

A further matter of concern is that if private companies find they are unable to operate with the desired secrecy under NIH guidelines, then they may carry out their research in other countries with less stringent requirements. Already some US corporations with interests in recombinant DNA research are supporting the activities of foreign companies.

Any attempt to exploit loopholes in current legislation, however, is not likely to be looked upon kindly by Congress, which last year held back from legislating on recombinant DNA research in the private sector largely on the basis of companies complying voluntarily with the NIH guidelines. No company has refused to comply with the technical aspects, covering for example biological and physical containment levels; but neither has any said that they can work with the complete guidelines as they now stand. 